\title{
Advanced level biology teachers' attitudes towards assessment and their engagement in assessment for learning
}

\author{
Sharon Bramwell-Lalor ${ }^{*}$, Marcia Rainford ${ }^{1}$ \\ 1 School of Education, University of the West Indies (Mona), Kingston, Jamaica \\ For correspondence: sharon.lalor@outlook.com
}

\begin{abstract}
This paper reports on a Mixed Methods study involving an investigation into the attitudes of advanced level biology teachers towards assessment and describes the teachers' experiences while being engaged in Assessment for Learning (AfL) practices such as sharing of learning objectives and peer- and self-assessment. Quantitative data were collected from 40 teachers using the researcher-constructed Teachers' Attitudes towards Assessment Questionnaire. Qualitative data were collected through discussions and interviews from six teachers who implemented AfL strategies. The findings revealed that advanced level biology teachers displayed highly favourable attitudes towards assessment. The teachers engaged in AfL had similar attitudes towards assessment as those who were not. Further there were no statistically significant differences in the teachers' attitudes towards traditional assessment and AfL. The teachers, however, described positive experiences while conducting AfL and highlighted the usefulness of practices such as the sharing of learning objectives and students' engagement in self-assessment. They also expressed the limitations of operating within a high-stakes examination environment. These findings have shown that the use of AfL methods in advanced level biology classrooms has value and can be practiced along with traditional assessment methods.
\end{abstract}

Keywords: advanced level biology, assessment for learning, formative assessment, attitudes towards assessment

\section{Introduction}

Assessment tends to generate negative sentiments by teachers (Wright, 2001). The need to set aside time to mark students' work and provide feedback may dampen teachers' enthusiasm towards assessment and serve as a deterrent from giving too many assessment tasks. Brooks (2002) proposed a view that teachers' attitudes towards assessment are often shaped from what they have "caught" by observing their own teachers while being students. This could be because assessment was not explicitly a part of their training courses which might have resulted in them learning how to teach without learning much about how to assess (Brooks, 2002; Heritage, 2007). They then consciously or unconsciously pass on their "caught" assessment practices to their students (Song \& Koh, 2010). This is of great concern because it suggests that unsuccessful or unsuitable practices could easily be learnt and passed on. Biased beliefs, perspectives and practices could also be upheld by teachers who have pre-formed unhealthy assessment attitudes. For example, teachers who have always been a part of the Assessment of Learning (or summative assessment) culture aimed at summarising students' level of attainment at the end of learning, are likely to create and foster a competitive atmosphere in their classrooms through the practice of ranking their students (Brooks, 2002). Competitiveness is a feature of traditional assessment practices that are deeply ingrained in many Caribbean classrooms where there is a culture of high-stakes external examinations such as those administered by the Caribbean Examinations Council (CXC). 
Recent research has been advocating that teachers make greater use of Assessment for Learning (AfL) (or formative assessment) practices as these have been shown to promote students' critical thinking and problem solving skills (Song \& Koh, 2010), which is a feature of creating life-long learners.

The literature portrays the relationship between teachers and assessment by focusing on how to improve assessment practises (e.g., Casa et al., 2007; Koh et al., 2010), teachers' emotions (e.g., Steinberg, 2008) beliefs and practices (e.g., Brown, 2004; Song \& Koh, 2010) and attitudes towards assessment (e.g., Ogan-Bekiroglu, 2008 \& 2009; Wen et al., 2006). Much has been done on AfL through researchers such as the Assessment Reform Group (2002, 2006, 2009), and Stiggins (2005, 2006). This paper seeks to explore teachers' views of AfL from a Caribbean context, and to provide some details of their practice of AfL. We join with other developing and developed countries in trying to better understand how to utilise assessment as a learning tool in classrooms heavily influenced by high-stakes examinations.

Assessment and Learning. Assessment plays a vital role by linking teaching and learning. It is the tool that allows students to provide evidence of their learning and also the avenue that gives teachers the well needed assurance that their hard work in classrooms is not in vain (Wiliam, 2014). Because of this important role, teachers must ensure that their assessment practices are aimed at providing the right kinds of evidence, and are not influenced by personal beliefs or biases. Teachers have to be willing to embrace any assessment practice that will benefit their students' learning.

Caribbean secondary school students use results of high stakes examinations to matriculate to other levels of the education system, and classroom teaching and assessment are mostly directed towards mastery of content in preparation for these examinations (Barrow \& Kent, 2015). Summative assessment is the primary approach utilized by teachers in preparation for these examinations.

Stiggins (2006) stated that schools have evolved into places where all students are expected to meet pre-set standards. In Jamaica the slogan of the Ministry of Education "every child can learn, every child must learn" supports this view. This slogan embodies the expectation that classroom practises should be geared towards ensuring each child is showing evidence of meaningful learning. In this paradigm, therefore, teachers need to understand and believe in the value of assessment as a learning tool, that is, supporting learning (Black \& Wiliam, 2012) - in other words, all students must have the opportunity to learn from the assessment process. This requires regular, day-to-day assessment utilising varied tasks to generate continuous evidence of students' learning (Assessment Reform Group, 2002). Using AfL strategies allows teachers to be provided with evidence of learning while it is occurring (Black \& Wiliam, 1998; OECD, 2005). The evidence can be acted on immediately such as through implementing required changes (Stiggins, 2005). Assessment for Learning strategies include the sharing of learning objectives and assessment criteria with students, using effective questioning techniques, providing detailed and appropriate feedback and allowing students to engage in peerand self-assessment (James, 2004).

Song and Koh (2010) however highlight that teachers need to prepare students for success in highstakes examinations, which could likely challenge AfL implementation. Students' success in these examinations is usually linked to teachers' performance. As a result, teachers in their classrooms are less likely to choose to incorporate AfL practices but instead resort to traditional practices they are used to in order to ensure that students can "pass the exams" (Barrow \& Kent, 2015). In a longitudinal study carried out in primary schools in England over eight years, it was reported that after the introduction of external tests, teachers' own classroom assessment gradually became more summative. Similarly, the students felt that teachers increasingly focused on performance outcomes rather than the learning process. In response to this, the students themselves began to adopt summative approaches to their work (Assessment Reform Group, 2006). It could be suggested 
therefore that teachers' attitudes towards assessment could influence how students respond to the assessment process.

Theoretical basis of assessment for learning. Assessment of learning (summative assessment) has been aligned to a behaviourist view of teaching and learning which focuses on the outcomes rather than the process of learning (Shepard, 2000). Constructivism largely supports the main principles of AfL. Teachers in constructivist classrooms establish the required non-threatening environment for students' to actively construct knowledge (Hodgson \& Pyle, 2010; James, 2006). In this environment students feel able to express their ideas which in turn provide teachers with the evidence of what the students don't know in order to better assist them. The teachers' role is to assist students who are really 'novices' to acquire 'expert' understanding of strategies required for problem-solving and meaningful learning such as through the use of classroom dialogue, open ended questioning and concept maps (James, 2006), which are AfL strategies.

Social constructivism speaks to learners learning from each other through social interaction. Dewey and Bruner advocated for education to be embedded in real-life experiences. Building on these ideas, Vygotsy proposed the idea of the 'Zone of Proximal Development' referring to the gap between what learners can do with assistance and what they do independently. They proposed that one way that learning gaps can be filled is through engagements with peers such as through peer teaching and assessment (Lindsay \& Clarke, 2001; So, 2004; Spiller, 2011).

Caribbean Assessment Framework. The Caribbean Examinations Council (CXC) administers two major examinations for Caribbean secondary school students: Caribbean Secondary Examinations Certificate (CSEC) for grade 11 students and the Caribbean Advanced Proficiency Examinations (CAPE) for students of grades 12 and 13. The CXC encourages the use of various classroom assessment methods that take into account the diverse learning needs of students. In addition to an external (usually written) examination, most CXC subjects are also assessed by school based or internal assessment components. Through internal assessment, it is expected that teachers will maximise the range of opportunities for their students to acquire and demonstrate critical skills and abilities associated with the subject during the learning process (CXC, 2013). The CXC requires that teachers provide students with the assessment criteria and give tasks that enable students to assess themselves. In addition, "...the process of assessment should provide timely feedback which the student uses to modify, extend and enhance...tasks" (CXC, 2007). These CXC assessment principles are aligned with AfL and are expected to be adopted and expressed by Caribbean teachers as they interact with their students through teaching and assessment activities.

The long-term culture of high-stakes examinations is unlikely to go away in the near future (Song \& Koh, 2010) and as such teachers are continuously preparing students for these exams. Teachers sometimes regard student-centred approaches to assessment as taking away from their "valuable teaching time" and often struggle with finding a balance between time for teaching and assessment. While conducting AfL requires teachers to be more deliberate in how they conduct classroom assessment and may require more effort Wren (2008) suggests that this could be redistributed for example by teachers shifting more assessment responsibility to students. Lave and Wegner's (1990) situated learning theory further suggests that when teachers engage in and learn first-hand about AfL and its benefits they are more likely to cultivate good attitudes leading to continued improvement in their practices.

Rationale for the study. This study was conducted to examine the types of attitudes that advanced level biology teachers have towards assessment and to deduce whether teachers' assessment attitudes impact on or are impacted by their engagement in AfL practices. The literature on AfL mainly focuses on the benefits of assessment and its impact on student outcomes. Not many studies have 
sought to link teacher's attitudes towards assessment with AfL. This study provides some information on teachers' attitudes towards assessment and insight into their AfL practices. The internal assessment component of the CXC examinations is expected to incorporate AfL principles; however, traditional summative assessment has dominated classroom practice in the Caribbean. This may create a tension that yields undesirable attitudes towards assessment and undermine AfL practices in the classroom. The results of this study will likely assist in indicating how teachers currently deal with the requirement of utilising AfL strategies in an external examination driven context.

Research Questions. Attempts were made to provide answers to the following research questions:

1. What are the attitudes of advanced level biology teachers towards assessment?

2. What are the experiences of teachers involved in assessment for learning in the teaching of advanced level biology?

Methodology. This study was designed to yield both quantitative and qualitative data. Forty (40) advanced level biology teachers responded to the researcher-designed Teachers' Attitudes towards Assessment Questionnaire (TAAQ). Twenty seven (27) of these teachers were involved in traditional assessment practices and thirteen (13) in AfL along with traditional practices. The AfL teachers were from 13 single-gender and co-ed secondary schools from rural and urban areas in Jamaica, and were selected to implement the practices based on their willingness. Table 1 shows that the teachers involved in AfL were heterogeneous with respect to age. Most were highly qualified but were mainly inexperienced in the teaching of advanced level biology. The majority of the teachers engaged in AfL $(85 \%)$ were female.

Table 1: Variables of teachers engaged in Assessment for Learning

\begin{tabular}{lll}
\hline & Variables & $\begin{array}{l}\text { Number of teachers } \\
\text { (and percentage) }\end{array}$ \\
\hline Age category (years) & $20-30$ & $3(23.0)$ \\
& $31-40$ & $5(38.5)$ \\
& $41-50$ & $2(15.4)$ \\
& $>50$ & $2(15.4)$ \\
Qualification & NR & $1(7.7)$ \\
& College Diploma ${ }^{\text {a }}$ & $2(15.4)$ \\
Number of years & Graduate Certificate/Diploma ${ }^{b}$ & $4(30.8)$ \\
teaching A level & Bachelor's Degreec & $12(92.3)$ \\
biology & Master's Degreed & $4(30.8)$ \\
& $<5$ & $5(38.5)$ \\
& $6-10$ & $2(15.4)$ \\
& $11-15$ & $1(7.7)$ \\
& $16-20$ & $1(7.7)$ \\
& $>20$ & $3(23.0)$ \\
\cline { 2 - 3 } & NR & $1(7.7)$ \\
a Obtained on completing graduate professional training. & \\
a Obtained on completing a minimum of two years of graduate work at a University.
\end{tabular}

The mean score of all 40 teachers on the TAAQ was calculated. Their mean scores on three subscales, and on the items related to traditional assessment and AfL were also calculated. Statistical analyses were carried out to determine significance of any differences observed between mean scores. Six of the AfL teachers' experiences, attitudes and views (Matthew, Joanna, Bill, Thelma, David and Viola) 
were explored through semi-structured interviews (see Appendix A) which were conducted in a sequential way (Cresswell \& Plano Clarke, 2007) over a period of three terms. The interview data along with ongoing conversations were obtained on visits to the institutions and by telephone. The data were transcribed, then coded to identify common or emerging themes, to look for individual variations, and generally to extract critical information that indicated teachers' attitudes towards assessment and how they responded to the use of AfL strategies.

The institutions involved in this study were those that follow the CXC's CAPE biology syllabus. The study started at the beginning of the school year (September) in classes where students were mainly being prepared for CAPE examinations in May of the following year. Black et al. (2003) in their paper: "A successful intervention, why did it work?" stressed that they allowed teachers to implement formative assessment strategies as they wished, depending on their own classroom contexts. They insist that this is the true nature of AfL. In the current study the teachers were encouraged to use the AfL strategies in their regular teaching and assessment (e.g., sharing of objectives and assessment criteria, ensuring that assessment activities matched objectives, employing formative 'comments-only' marking). In addition, three teachers placed extra focus on peer group learning (Bill, David, Joanna), while three focused on students' self assessment (Charmaine, Georgia, Matthew - Mathew was interviewed from this group). The researchers constructed a self-assessment feedback form that could be used to guide the students' reflections (Appendix B). The teachers in the control group were not required to do anything different or additional to their regular instructional strategies.

Instrumentation. The "Teachers' Attitudes towards Assessment Questionnaire" consisted of 20 Likerttype items and covered three subscales namely:

- Teachers' opinions on the purpose of assessment (4 items)

- Teachers' practise of assessment (11 items); and,

- Teachers' interest in and enjoyment of assessment (5 items)

In addition, 10 of the 20 items specifically sought teachers' views on traditional assessment practices while the other 10 represented those of AfL. The overall reliability estimates by Cronbach's alpha on this instrument was found to be .715, which is acceptable for research purposes (Rudner \& Schafer, 2002).

\section{Results}

Research Question 1: What are the attitudes of advanced level biology teachers towards assessment?

The questionnaire (TAAQ) provided the majority of the data to answer to this question. The possible scores on the TAAQ ranged from a minimum of 20, indicating poor attitudes towards assessment, to a maximum of 100. Table 2 indicates that the teachers obtained a mean score of 78.30 indicating fairly high, favourable attitudes towards assessment. The difference between the mean score of the teachers involved in AfL and those not involved was not statistically significant based on independent $\mathrm{T}$ test results. A Cohen's d value of 0.169 was obtained based on mean differences of teachers involved in AfL and those not involved.

Table 2. Descriptive statistics on teachers' attitudes towards assessment based on treatment

\begin{tabular}{cccc}
\hline Group & $\mathbf{n}$ & Mean & SD \\
\hline Experimental & 13 & 77.46 & 7.79 \\
Control & 27 & 78.70 & 6.84 \\
& & & \\
\hline Total & 40 & 78.30 & 7.09 \\
\hline
\end{tabular}


Attitudes of teachers towards Traditional Assessment and Assessment for Learning. A possible high score of 50 was available on each set of 10 items related to traditional assessment and AfL on the TAAQ. Participants scored a slightly higher mean on the traditional items compared to the AfL items. The difference between these scores was not statistically significant $(t=-.514 ; p=.610)$. Even though the difference in teachers' means scores on both types of items was not statistically significant the effect size (Cohen's $d$ ) was calculated to determine practical significance and a value of 0.422 was obtained. Further, there were no significant differences between the mean scores of teachers involved in AfL and those who were not (Table 3).

Table 3. Descriptive statistics on teachers' attitudes towards traditional assessment and AfL

\begin{tabular}{|c|c|c|c|c|c|}
\hline \multirow[t]{2}{*}{ Group } & \multirow[b]{2}{*}{$\mathrm{n}$} & \multicolumn{2}{|c|}{ Traditional items } & \multicolumn{2}{|c|}{ AfL items } \\
\hline & & Mean & SD & Mean & SD \\
\hline Experimental & 13 & 39.46 & 5.03 & 38.00 & 3.92 \\
\hline Control & 27 & 39.44 & 4.92 & 39.26 & 3.45 \\
\hline Total & 40 & 39.45 & 4.89 & 38.85 & 3.61 \\
\hline
\end{tabular}

Subscales: 1) Teachers' opinions on the purpose of assessment. The teachers obtained a mean score of 16.33 (Table 4) out of a possible 20. The majority of the teachers (97.5\%) indicated that the main purpose of assessments is to monitor the teaching-learning process rather than to give grades. It was not surprising that the majority of the teachers $(75 \%)$ believe that assessment should be integrated into the teaching process rather than being a terminal exercise. They also generally believe $(67.5 \%)$ that there are other ways besides classwork, homework and tests that can indicate what a student has learnt.

Despite these favourable views of the purpose of assessment, the interview data seemed to suggest that the teachers mainly use assessments to prepare students for external exams. Matthew, for example, stated that a regular practice of his is to "spot" (predict) questions coming on examinations and use them to prepare his students. He also stated that he marked his classroom tests 'hard', as this would serve his students better on the external exam.

Table 4. Teachers' questionnaire mean scores on three subscales based on treatment group

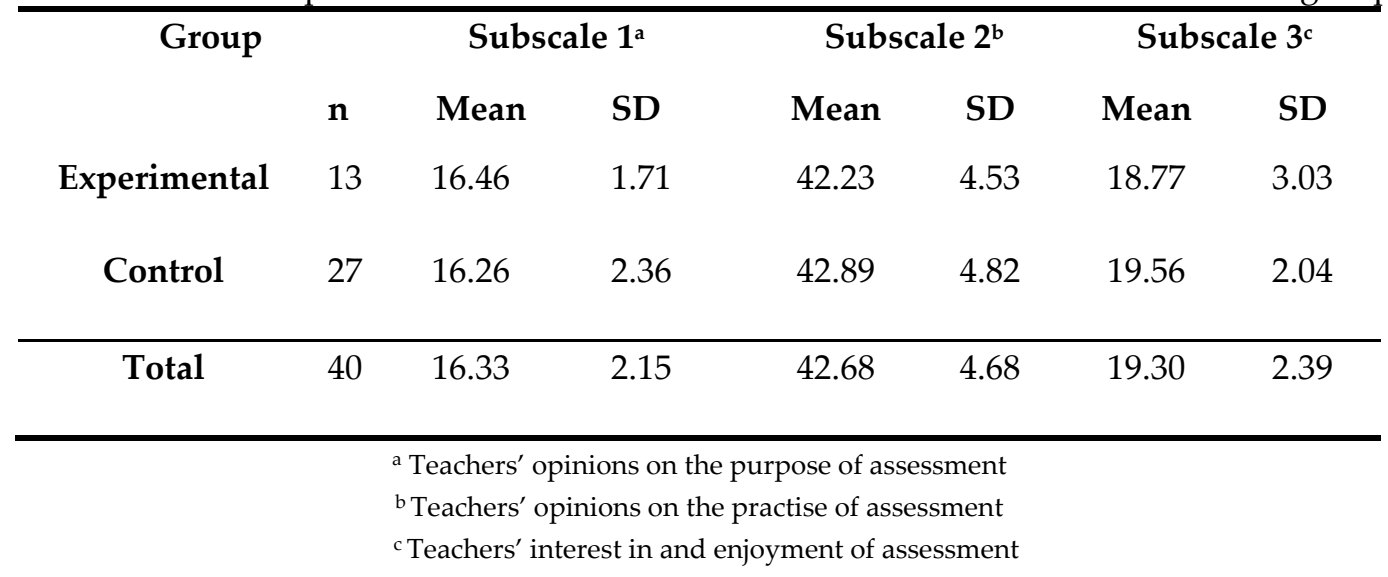

A second purpose of assessment that was gleaned from the interviews is to generate a pre-set number of grades as required by institutions. Joanna said "...you have to generate all these worksheet 
grades." Bill explained that he administers a graded test at the end of every topic in order to have a grade for the students' record. At David's school regular testing is also done and he explained that this was limiting as any assessments outside of that schedule is difficult to accommodate (particularly if they will not be graded as is one practice of AfL).

2) Teachers' opinions on the practise of assessment. A mean score of 42.68 (Table 4) out of a possible 55 was obtained on this subscale. With respect to the timing of assessments, a large number of the teachers $(67.5 \%)$ indicated that they should not wait until a topic is finished to assess it. Despite this belief, only $50 \%$ of the teachers indicated that they assess at other times during teaching (for example, by giving pre-tests). The interview data revealed that Bill, Thelma, David and Joanna are among the $50 \%$ who give regular assessment tasks during the teaching of specific topics. Bill further pointed out that he allows students who don't perform as they should to re-do tests under "more relaxed conditions" such as at home. In some cases he also gives them a worksheet on the topic to complete on their own.

The teachers' survey results indicated that a variety of assessment tasks should be used (95\%), which should be aimed not only at the basic knowledge and re-call level but at higher levels (87.5\%). They also believe that assessment criteria should be shared with the students $(82.5 \%)$. The teachers largely believe (95\%) that comments should be written on students' classwork, homework and other assessment tasks. They also indicated that they use information gained from the students' performances to modify their own teaching activities. Teachers' practices related to assessment criteria, comments-only marking and feedback will be further addressed in the second research question.

Despite these positive responses about a variety of assessment tasks, Bill stated that he mainly uses pencil and paper tests and practical exercises. Only a few of the teachers (30\%) stated that they allow their students to grade the work of their peers. Thelma explained how she did it in her class: "sometimes they would do the work and I would pass the papers around and they mark the paper and they'd grade it themselves and then I would go back...to make any adjustments - if there are any adjustments to be made probably... the person grading was probably grading too hard or too lenient - just to show the difference." She explained that students' grades were often similar to hers but thought that sometimes the students were "too lenient". She explained that those who she thought were too generous were the ones who had not grasped the concept very well. As a result they assigned their marks based on their own understanding and expectations.

3) Teachers' interest in and enjoyment of assessment. The teachers obtained a mean score of 19.30 (Table 4) out of a possible 20 on this subscale. The majority of the teachers $(62.5 \%)$ suggested that the requirements of the CAPE syllabus do not usually prevent them from being interested in their students' learning. The interview data however revealed otherwise as the majority of the teachers expressed feelings related to the demands of the CAPE syllabus. According to Thelma, she is largely focused on finishing the syllabus, a view supported by Bill who bluntly stated "finishing the syllabus is critical". Bill explained further that students will even pressure teachers to move on whether they have completely "caught on" to the topic or not. Viola argued that "the parents don't want to hear that the syllabus is not finished", and expressed anxiety in the CXC's exam dates seemingly being set "earlier and earlier each year". She said "it feels as if there is no time to complete the syllabus and revise".

Bill pointed out that because of the limited resources he spent much time researching and gathering material to prepare for classes. The teachers felt that the demands of the syllabus often went against the use of AfL strategies, or ensuring that students were learning. According to Joanna "the time is limited...there's a lot of things to cover and you are pressured at all times..." Viola opined "these are 
brilliant ideas (meaning the assessment strategies) but with the timing and structure of the exam these methods are time consuming, if you utilise them fully you will never finish the syllabus."

Research Question 2. What are the experiences of teachers involved in assessment for learning in the teaching of advanced level biology?

The AfL practices included sharing of learning objectives and assessment criteria, peer and self assessment, and provision of effective feedback.

The sharing of learning objectives and assessment criteria. The teachers reported that they shared learning objectives at the start of the lessons, or a topic. Bill explained that at the start of a topic he would say "this is what we're gonna be doing..." According to Thelma, the sharing of objectives should be emphasised because it allows teachers to focus the lesson for the students. She further said that learning objectives could also be used as links to a follow-up class where students could be invited to evaluate their current state of learning against the objectives. She explained that, for example, a student could say "Miss I learnt the objectives as how you stated it or how it is given on the paper...or I have not yet learnt all of this or I'm not understanding". Thelma explained that this would assist her in planning for future lessons. However, she pointed out that she did not share learning objectives in each class because if she was late for a class she would instead focus on finishing a concept. She explained "...you want them to understand then when you see so much to do and the time given, that part of one gets caught up...in finishing...". Bill mentioned that although he asked his students to follow up on the objectives on their own he did not know whether they were actually doing so. He admitted, however, that he should take some of the blame because he did not think he "really encouraged them to do that..." Some of the teachers appeared to share assessment criteria with their students in a variety of ways but only informally. Viola reported "...if a student does a 'good piece of work' then I would share it with the class so at least they would have an idea as to what they needed to have written to get an " $\mathrm{A}$ "..."

Feedback. All of the teachers expressed that they had never engaged in the practice of withholding grades and only placing comments on students' papers (formative 'comments-only' marking). Bill stated "in my time of teaching - which is not too long - that idea never really came home to me in terms of...you could...mark questions and not necessarily putting any grade on the paper..." . He said "the response was good when I used it. I mean I didn't use it all the time but...I think the response from them was favourable... even though it was new to them... they kind of liked the idea some of them". Thelma kept a note of the numerical grades in her mark book until "...after assuming that they had the week to go through the paper and see where they go wrong." One of the reasons Viola gave for not using this strategy more often was: "...you are so set in your ways... you're so accustomed to the other way around". The teachers were asked how the students responded on occasions when there were no grades on their papers. One teacher said "of course they'd come back to ask what the grade was". Joanna said "It depended on whether they did well or not". Viola observed that the students seemed to be more responsive during discussions when a grade was absent, explaining that they usually tend to get distracted when a grade is present. She explained "normally when they see the grade they just look and they add up..." Joanna similarly stated "...they'll run for their calculator" and punch in numbers. Viola added that the students spend time searching for 'half-mark' more, and as a result "...they're finished with you - they completely tune out".

Joanna tried to ensure that her students were following up on her written comments during regular class time by 'going through' the assessment with them. She observed however that some students did follow up on her comments on their own outside of class time. The teachers provided some insight on how they used feedback from the students' work. According to Viola "you tried to modify 
your teaching based on ...the comments... made. Like if they weren't understanding a particular topic or its boring ... you'd try to vary...how to present it..." Thelma stated similarly: "if for...a particular topic or section, ... the entire class did not do as good as I think they should or ought to - that basically shows it was an individual problem - probably it was my approach...". Joanna recommended that if teachers are not going to put grades on classroom assessment activities then it was best to introduce it early in teaching and explain to the students why they were using that approach. In that way the students would be more prepared when they did not see grades on their paper.

Peer learning groups. Bill was enthusiastic in his comments on this strategy. He stated: "It really worked...I've tried it with the grade 11 students and the students said 'sir we really appreciated it' ...I tried it once or twice and the students really...most of the students seemed to benefit so in terms of a difficult topic especially like with plant reproduction." He further commented: "I will always use peer grouping - I think it's very good, very good and I've seen where it works for CAPE and where it works for CSEC."

In Joanna's class students engaged in peer-assessment of group presentations. "It went well" she said "...the presentations were quite good, and also I looked at how they assessed if it coincided with mine." She gave them a mark scheme which guided their scoring, stating that their marks usually coincided with hers. When asked how the students responded to peer assessment she said "at first they were kinda reluctant but...they eventually buckled down." Joanna pointed out one aspect of peer grouping that was a challenge for many of her students. They found it difficult to meet outside of class time to do group activities, because of other appointments that took place off the school compound. She therefore has to sometimes allow groups to meet in her class time.

Self assessment. Charmaine and Georgia used the researcher-constructed self assessment form (Appendix B) which students completed after each topic. Georgia's students also assessed their level of understanding of each objective by using the indicators: totally, partially, none at all. Students were also asked to indicate whether they needed further help with the indicated objectives. Matthew asked his students to rate their understanding of the objectives on a scale of $1-5$ at the end of a Module. In all cases the teachers analysed the students' responses and used the information to modify instructional strategies or conduct revision sessions. One-to-one or small-group sessions were also used to address specific concerns.

Matthew highlighted the need for students to be trained and supported in self- assessment practices until they are comfortable doing it on their own. He feels that the students are not at the level of maturity to develop and stick to a schedule that makes them able to do certain tasks (for example reading textbooks) on their own. Matthew stated that although he had asked the students to engage in self assessment he "did not believe in it". Further probing indicated the reason. In his opinion, students overrate or underrate themselves when they engage in self assessment. For example he said a student may say "I don't know anything", and when asked to rate himself on an objective he gives himself a ' 1 ' or ' 2 ' (meaning the highest grades).

\section{Discussion}

Teachers' attitudes towards assessment. The teachers in this study had similar favourable attitudes towards assessment that generally reflected their understanding of the nature of assessment. The weak Cohen's d value of 0.169 suggests that both the teachers engaged in AfL and those who did not, had similar influences on their practice. The teachers in this study indicated that assessment should be integrated into the teaching process - a view supported by Heritage (2007), Markwick et al., (2003), OECD (2008) and Shavelson (2006), but which runs counter to the traditional purpose of assessment. The teachers understood that AfL is focused on monitoring the learning process rather than on awarding grades and that a variety of assessment methods should be utilised in the learning process. 
Stiggins and Chappius (2005) imply similarly, that the purpose of assessment is varied and one type of assessment approach cannot fit all needs, therefore the teachers need to be familiar with the many types of assessment methods.

The teachers' philosophies about AfL as expressed in the questionnaire results did not always match their practices. This represents a conflict in teachers' understanding of assessment and how they execute their understanding in classrooms. As stated before, the performance of Jamaican students on external exams is largely used as an indicator of students' achievement, as well as teachers' abilities. So, despite teachers' predominant view that assessment should be used for monitoring the learning process, they seemed unable to remain committed to that purpose when faced with pending high-stakes examination. Aitken (2000) reported a similar observation for a group of 20 secondary school teachers stating that school exams are used as a tool for external exam preparation. The teachers in that study expressed close links between their internal school summative assessments and results of external examination and as such engaged in the practice of replicating both time constraints and content mastery, in their internal examinations, rather than focusing on learning in general. Marking practices are also influenced. Aitken (2000) reported on a teacher who stated "I tend to mark hard and students tend to do better in the external exam" ( p. 16). A similar sentiment was expressed by Butler and McMunn (2006) who opine that educators often struggle between a focus on how to increase their students' grades, while ensuring that their students are really learning. In this kind of atmosphere, they concluded that teachers choose the former and resort to short-term strategies designed to increase the students' chances of passing exams.

Another way in which the external examination served to constrain the teachers' implementation of AfL was in the types of tasks used in the teaching-learning process. The assessment tasks used were primarily those mandated by the CXC's syllabus (e.g., practical exercises). Practical activities are required to generate school based assessment grades which contribute to the students' earned grade on the final external examinations. Because of this, teachers would want to ensure that students have as many opportunities as possible to earn maximum grades, rather than using assessment tasks that will not yield school based assessment grades.

Teachers mainly used assessment to generate mark-book grades and to prepare students for external examinations. The policy for grades varies from school to school, but generally there is a requirement that each student should have a series of grades that reflect his/her performance for the duration of a term or semester. Teachers reported that this requirement sometimes reduced the amount of time available for attempting multiple modes of assessment. This reveals a constraint in the implementation of AfL by teachers as they seek to balance the summative requirements of their Institutions, while trying to provide helpful feedback to the students as they are learning which would aid their chances of succeeding on external examinations.

Multiple modes of assessments are important because they will provide more than one way for a student to express his/her learning (Tomlinson, 2008). Tomlinson explains further that if a student performed poorly on one type of format that was not necessarily an indicator of failure because another form of assessment could possibly allow the student to communicate what he/she really knows. This also suggests that the best student found by using one type of assessment method may not necessarily be the best student if another method is used (Danili \& Reid, 2005). The teachers in the current study had positive beliefs about the benefits of multiple assessment modes, but there were factors that militated against using them because they most regularly used the end of topic test. Some of these factors might have contributed to these teachers' inability to yield higher scores on the AfL questionnaire items. It is possible that their involvement in AfL might have allowed them to provide more thoughtful and informed responses to the items than their counterparts who scored marginally higher but were not involved in AfL (Table 3). 
Teachers' assessment practices indicated extensive use of past papers and reports from examining bodies indicating the tremendous influence that external exams have on their classroom practices. This once more highlights negative influences on the implementation of AfL. The practice of "spotting" was evident in which teachers try to identify trends in which topics were tested over a period of time. A prediction is then made as to what topic will appear on the current exam. Students are then prepared by the teachers to answer any question that comes on that topic. This practice means that many topics likely get ignored in the elimination process. A student may therefore end up passing an exam based on knowledge of a topic that s/he is well-prepared to answer rather than on his/her genuine understanding of the content gained through well-developed thinking processes. Kim and Noh (2010) warned that the emphasis on content in preparation for external exams could be detrimental to the development of problem solving processes because students will choose to focus on simply memorizing facts without learning how to use this knowledge at a later date.

Teachers' AfL Practices. The teachers generally reported positive experiences of AfL, however, they did not regularly implement the strategies in their classrooms. Positive attitudes therefore did not necessarily lend themselves to "best" practices in assessment. The Cohen's d value of 0.422 which is trending towards medium suggests some practical significance in further exploring the relationship between how teachers view AfL and traditional assessment as compared to what they actually practice.

The sharing of learning objectives and assessment criteria. The sharing of learning objectives served as an avenue for feedback to teachers and students, which is a necessary component of AfL (Clarke, 2005). Clarke observed that sharing objectives enable students to be more focused on learning rather than 'getting through' the activity at hand. Spavold (2005) also reported similar benefits from sharing objectives among 11 to 18 year old science students in the UK. Even though teachers in the current study showed appreciation for the sharing of learning objectives, this was not always done further highlighting the gap between teachers' desired and actual assessment practices (Clarke, 2005; McMillan, 2003). Gioka (2007) observed from her study among nine secondary school biology teachers that most of them believed in formative assessment (AfL) but were not actually implementing its practices (e.g., sharing of assessment criteria).

In order for students to assess their own work, they need to have a clear picture of their learning targets (Wiliam, 2005). Knowledge of these criteria positions them to monitor their own progress towards learning goals. Assessment for Learning requires a shift in control of assessment practices more towards the students (Prezler, 2004). Willis (2007) states that assessment has been used as a 'power' and 'control' tool by teachers and Jamaican teachers have traditionally been exposed to this model. It is, therefore, understandable that many teachers will find it difficult and may even be reluctant to change their approach towards assessment if it means relinquishing some of their control.

Feedback. The formative practice of 'comments-only' was new and the teachers tried it on a few occasions. Some of the reasons the teachers gave for not using this strategy more often included their difficulty to change their usual way of doing things in the classroom and the school's requirement to generate grades. Black et al., (2004) similarly pointed out that school policies can be unsupportive of AfL practices. They reported that secondary school teachers in the UK were concerned with using 'comments only' marking because it conflicted with school policy. Yet others were fearful of parents' reactions to the practise. There was no indication of negative reactions in the current study from the school administration to the use of "comments only" marking in classroom assessments.

Smith and Gorard (2005) reported on a study conducted in the UK on Year 7 Secondary school students in which they were not comfortable with only receiving comments on their papers. In an exam-oriented school, students tend to prefer to have grades as a means of evaluating themselves and 
establishing their position in relation to their peers. Under those conditions teachers may be tempted to resort to the easier practice of giving grades to satisfy students' wishes and demands and to meet the school's requirements as was evident in the current study. The teachers recommended that the introduction of AfL strategies such as "comments-only marking" is best done early in secondary school years and should be clearly explained to the students. In that way the students would be more prepared for occasions when they do not see grades on their paper. The students in the study by Smith and Gorard (2005) similarly recommended that the aims of such interventions should be explained clearly to students before they are implemented.

Though some teachers indicated that they were giving the students opportunities to use the data garnered from the assessment process to improve on their learning, this was not done consistently. Successful implementation of AfL requires that the feedback process is managed and monitored to ensure that students actually use the assessment data to improve their learning. Clarke (2005) stated that teachers rarely give students time in class to read comments and make improvement to their work, because of the teacher's pressure to 'finish' the syllabus. This is regrettable because there is a level of satisfaction when teachers observe that their students are following up on their comments on their own. This is one of the signals that students are becoming more involved in the learning process and could encourage teachers in having even more positive attitudes towards assessment based on high satisfaction levels.

Peer learning and assessment. The teachers who allowed their students to be engaged in peer learning reported positive benefits similar to Tessier (2007). The practice of peers interacting with peers occurred mainly on teacher-directed, planned occasions, but there was also evidence of spontaneous peer learning groups being formed in this study. Although the activities in the groups were varied, the emphasis in most of the classes was on group presentations and peer assessment. The sharing of learning objectives and assessment criteria as well as peer teaching also occurred.

Although students were allowed to grade the work of their peers this was not done with close guidance

by their teachers and did not occur very often. It appears that the reason for this is that teachers wanted to continue to be 'in charge' of assessment. As previously mentioned, one of the challenges to implementing AfL practices is for teachers to be able to shift the 'control' from themselves to their students (Black et al., 2004; Willis, 2007). It appears that some teachers are able to accomplish this more easily than others (Lee \& Wiliam, 2005).

Students may need to be trained in order to ensure they practice strategies such as self assessment properly. Noonan and Duncan (2005) found that some high school teachers did not engage their students in peer or self assessment because they doubted the students' ability to be mature enough to accurately and fairly carry out such tasks. Such lack of conviction on the teacher's part could influence their enjoyment of assessment and in turn the types of attitudes they have towards assessment.

It was anticipated that teachers in the experimental group might have scored a higher mean on the AfL items compared to their counterparts who were not engaged in it. This did not occur, and the interview data revealed that the teachers felt that the demands of the syllabus often went against the regular use of AfL strategies. Classroom learning seemed to be greatly threatened by the pressure to 'finish the syllabus'. Overall, it was evident in the teachers' responses that preparation for the external exam was a priority and of paramount importance. The teachers in the study were entirely willing to try 'new things', but their inability was further heightened by the fact that stakeholders (such as parents) tend to hold the administration accountable for students' level of achievement and the administration in turn holds the teachers responsible (Assessment Reform Group, 2009). 
The teachers in this study had positive attitudes towards AfL but this did not necessarily lead to consistent implementation practices in their classrooms. It cannot be assumed that teachers with positive attitudes towards assessment will consistently carry out sound assessment practices. This apparent gap between teachers' attitudes and their actual performance seems due in part to the unintended consequences of high-stakes examinations.

\section{Conclusions and Recommendations}

The teachers in this study had favourable attitudes towards assessment. This was true irrespective of their involvement in AfL. A possible explanation for this is that the task of finishing the syllabus and ensuring that students are prepared for external exams was a unifying factor in how assessments are conducted. This seemed to act as a driving force resulting in assessment practices that were largely similar. Another reason we are suggesting for the similar attitudes is that most of the teachers involved in this study were new to advanced level biology teaching and even though they desired to be innovative, they were being socialised into the existing assessment culture. There is therefore a need for continued training of pre-service and in-service teachers in various instructional practices such as AfL strategies, with tangible advice provided for how these can be implemented in their classrooms (e.g., training students, being flexible - both teachers and students may need to negotiate on the best way and time to implement strategies). Teachers should be provided with the confidence by supervisors that they can practice these strategies in class whenever they desire.

Teachers valued the AfL strategies but expressed that the syllabus they were using was demanding and that the time available to complete the syllabus was limited. Finishing the syllabus was a priority for them and this in turn influenced their teaching and assessment practices and largely prevented them from using AfL strategies more regularly. It is therefore difficult to transform AfL strategies successfully into classrooms as long as teachers are operating in a high-stakes environment. School administrations need to provide support for teachers such as adequate resource materials to make lesson planning and implementation easier. They could also review the requirements for the number of grades for mark books to leave teachers with some room to conduct assessment that will not necessarily be for recording purposes.

Teachers need to create and utilise opportunities such as through department meetings, workshops and seminars to share with each other strategies for delivering the syllabus in a timely manner. They could also share success stories of their classroom about AfL. Tangible measures need to be established to support and assist teachers in dealing with the tension between high-stakes summative exams and AfL practices.

Seeing that the high-stakes examinations culture will continue to exist in the Caribbean, school administrators should ensure AfL strategies are introduces at the earliest grades in the secondary school system to allow for understanding of the methods as well as training and adjustment to the use of the methods. They should also encourage the infusion of AfL strategies alongside the traditional approaches to classroom teaching, learning and assessment. These strategies need to be explored further to find ways to reduce the gap between teachers understanding of AfL and their ability to translate this into their classroom practices in a sustained manner.

\section{References}

Aitken, R. (2000). Teacher perceptions of the use and value of formative assessment in secondary English programmes. SET: Research Information for Teachers 3, 15-20. http://www.nzcer.org.nz/system/files/set2000_3_015.pdf (accessed March 2013)

Assessment Reform Group. (2002). Assessment for Learning: 10 Principles. University of Cambridge School of Education. http://assessmentreformgroup.files.wordpress.com/2012/01/10principles_english.pdf (accessed March 2013) 
Assessment Reform Group. (2006). The role of teachers in the assessment of learning. University of Cambridge School of Education. http://www.nuffieldfoundation.org/sites/default/files/files/The-role-of-teachers-in-the-assessment-of-learning.pdf (accessed January 2013).

Assessment Reform Group. (2009). Assessment in schools: Fit for purpose? A commentary by the teaching and learning research programme. Economic and Social Research Council. TLRP Commentaries, 13. Teaching and Learning Research Programme (TLRP). http://www.tlrp.org/pub/documents/assessment.pdf. (accessed January 2013).

Barrow, D., \& Kent, N. (2015). Strategies teachers use in helping students overcome the eleven-plus barrier: A multi-site case study of high-stakes testing in Belize. Caribbean Educational Research Journal, 3 (1), 2-17. http://www.cavehill.uwi.edu/fhe/education/cerj/cerj-april-2015-june-01,-2015.aspx (accessed July 2015).

Black, P., \& Wiliam, D. (1998). Inside the black: Raising standards through classroom assessment. Phi Delta Kappan, 80(2), 139148. http://www.spd.dcu.ie/site/teaching_today/documents/raisingstandardsthroughclassroomassessment.pdf (accessed July 2010)

Black, P., \& Wiliam, D. (2012). Assessment for Learning in the Classroom. In Gardner, J. (Ed.) Assessment and Learning (pp. 11-32). London: Sage Publications.

Black, P., Harrison, C., Lee, C., Marshall, B., \& Wiliam, D. (2003). A Successful Intervention - Why Did It Work? Paper presented at the Annual Meeting of the American Educational Research Association, Chicago 23 April 2003 https://www.researchgate.net/publication/258423109_A_successful_intervention_why_did_it_work (accessed October 2015).

Black, P., Harrison, C., Lee, C., Marshall, B., \& Wiliam, D. (2004). Working inside the black box: Assessment for learning in the classroom. Phi Delta Kappan, 86(1), 9-21. http://datause.cse.ucla.edu/DOCS/pb_wor_2004.pdf (accessed April 2015)

Brooks, V. (2002). Assessment in secondary schools: The new teacher's guide to monitoring, assessment, recording, reporting and accountability. Buckingham: Open University Press.

Brown, G. T. L. (2004). Teachers' conceptions of assessment: Implications for policy and professional development. Assessment in Education, 11(3), 301-318.

Butler, S. M., \& McMunn, N. D. (2006). A teacher's guide to classroom assessment: Understanding and using assessment to improve student learning. San Francisco: Jossey-Bass.

Caribbean Examinations Council. (2013). SBA Handbook for teachers.

Caribbean Examinations Council. (2007). Guidelines to facilitate development of standards and assessment procedures for locally developed and certified programme.

Casa, T. M., McGivney-Burrell, J., \& DeFranco, T. C. (2007). The development of an instrument to measure preservice teachers' attitudes about discourse in the mathematics classroom. School Science and Mathematics, 107(2), 70-80.

Clarke, S. (2005). Formative assessment in the secondary classroom. London: Hodder Murray.

Cresswell, J., \& Plano Clarke, V. L. (2007). Designing and conducting mixed methods research. Thousand Oaks, CA: Sage Publications.

Danili, E., \& Reid, N. (2005). Assessment formats: do they make a difference? Chemistry Education Research and Practice, 6, 204212.

Gioka, O. (2007). Assessment for learning in biology lessons. Journal of Biological Education, 41(3), 113 - 116.

Heritage, M. (2007). Formative assessment: What do teachers need to know and do? Phi Delta Kappan. 89 (2).

Hodgson, C., \& Pyle, K. (2010). A Literature Review of Assessment for Learning in Science. Slough: National Foundation for Educational Research (NFER) https://www.nfer.ac.uk/publications/AAS01/AAS01_home.cfm (accessed September 2015).

James, M. (2004). Assessment for learning: What is it and what does research say about it? University of Cambridge. http://www.learntolearn.ac.uk/home/003_introduction/001_assessment_for_learning_MJ4.doc. (accessed October 2015)

James, M. (2006). Assessment, teaching and theories of learning. In J. Gardner (Ed.), Assessment and learning (pp. 47-59). London: Sage Publications.

Kim, M. K., \& Noh, S. (2010). Alternative mathematics assessment: A case study of the development of descriptive problems for Elementary School in Korea. Eurasia Journal of Mathematics,Science \& Technology Education,6(3), 173-186.

Koh, K., Lim, L. \& Habib, M. (2010, August). Building teachers' capacity in classroom-based formative Assessment. Paper presented at the 36th International Association for Educational Assessment (IAEA) Annual Conference, Assessment for the Future Generations. Bangkok, Thailand (August 2010). http://www.iaea.info/documents/paper_4d520f18.pdf (accessed August 2015).

Lave, J., \& Wenger, E. (1990). Situated learning: Legitimate peripheral participation. Cambridge, UK: Cambridge University Press.

Lee, C., \& Wiliam, D. (2005). Studying changes in the practice of two teachers developing assessment for learning. Teacher Development, 9 (2), 265-283.

Lindsay, C., \& Clarke, S. (2001). Enhancing primary science through self- and paired-assessment, Primary Science Review, 68, $15-18$.

Markwick, A., Jackson, A., \& Hull, C. (2003). Improving learning using formative marking and interview assessment techniques. School Science Review, 85(211), 49-55.

McMillan, J. H. (2003). Understanding and improving teachers' classroom assessment decision making: Implications for theory and practice. Educational Measurement: Issues and Practice, 22, 34-43.

Noonan, B., \& Duncan, R. (2005). Peer and self-assessment in high schools. Practical Assessment, Research and Evaluation, 10(17). http://pareonline.net/pdf/v10n17.pdf (accessed August 2015). 
Ogan-Bekiroglu, F. (2008). Utilization of attitude maps in evaluating teachers' attitudes towards assessment. Asia-Pacific Forum on Science Learning and Teaching, 9 (1), Article 2. http://www.ied.edu.hk/apfslt/v9_issue1/feral/index.htm\#con (accessed September 2015).

Ogan-Bekiroglu, F. (2009). Assessing assessment: Examination of pre-service physics teachers' attitudes towards assessment and factors affecting their attitudes. International Journal of Science Education, 31(1), 1-39.

Organisation for Economic Co-operation and Development, (2005). Formative assessment: Improving learning in secondary classrooms. Policy Brief. http://www.oecd.org/edu/ceri/35661078.pdf (accessed January 2015).

Organisation for Economic Co-operation and Development, (2008). Assessment for learning - the case of formative assessment. OECD/CERI International Conference on -Learning in the 21st Century: Research, Innovation and Policy. http://www.oecd.org/site/educeri21st/40600533.pdf (accessed January 2015).

Prezler, R. (2004). Cooperative concept mapping. Journal of College Science Teaching, 33(6), 30-35.

Rudner, L.M., \& Schafer, W.D. (2002). What teachers need to know about assessment, Washington, DC: National Education Association http://echo.edres.org:8080/nea/teachers.pdf (accessed January 2015).

Shavelson, R. J. (2006). On the integration of formative assessment in teaching and learning with implications for teacher education. Paper prepared for the Stanford Education Assessment Laboratory and the University of Hawaii Curriculum Research and Development Group. http://web.stanford.edu/dept/SUSE/SEAL/Reports_Papers/Paper.htm (accessed January 2015).

Shepard, L. (2000). The role of assessment in a learning culture. Educational Researcher, 29(7), 4-14.

Smith, E. \& Gorard, S. (2005). 'They don't give us our marks': the role of formative feedback in student progress, Assessment in Education, 12(1), 21-38.

So, W. M. W. (2004). Assessing primary science learning: Beyond paper and pencil assessment. Asia-Pacific Forum on Science Learning and Teaching, 5(8). https://www.ied.edu.hk/apfslt/v5_issue2/sowm/ (accessed January 2015).

Song E. \& Koh, K. (2010, August). Assessment for learning: Understanding teachers' beliefs and practices. Paper presented at the 36th International Association for Educational Assessment (IAEA) Annual Conference in Bangkok, Thailand. http://www.iaea.info/documents/paper_2fb234cf.pdf (accessed September 2015).

Spavold, Z. (2005). Using formative assessment to raise pupil motivation: a small classroom-based study. School Science Review, 86(317), 119-123.

Spiller, D. (2011). Assessment matters: Self assessment and peer assessment. http://www.waikato.ac.nz/tdu/pdf/booklets/ 9_SelfPeerAssessment.pdf (accessed July2015).

Steinberg, C. (2008). Assessment as an 'Emotional Practice'. English Teaching: Practice and Critique, 7(3), 42 - 64. http://files.eric.ed.gov/fulltext/EJ832216.pdf (accessed October 2015).

Stiggins, R. (2005). From formative assessment to assessment for learning: A path to success in standards-based schools, Phi Delta Kappan, 87(4), 324-328.

Stiggins, R. (2006). Assessment for learning: A key to motivation and achievement. Edge, 2 (2), 3-19.

Stiggins, R. J., \& Chappius, J. (2005). Using student-involved classroom assessment to close achievement gaps. Theory Into Practice, 44 (1), 11-18.

Tessier, J. (2007). Small-Group peer teaching in an introductory biology classroom. Journal of College Science Teaching, 36(4), 6469.

Tomlinson, C. (2008). Learning to love assessment. Educational Leadership, 65(4), 8-13.

Wen, M. L., Tsai, C., \& Chang, C. (2006). Attitudes towards peer assessment: a comparison of the perspectives of pre-service and in-service teachers Innovations in Education and Teaching International,43(1), 83-92.

Wren, D.G. (2008). Using formative assessment to increase learning. Research report from the Dept of Research, Evaluation and Assessment, Virginia Beach City Public Schools. http://www.vbschools.com/accountability/research_briefs/ResearchBriefFormAssmtFinal.pdf (accessed October 2015).

Wiliam, D. (2005). Keeping learning on track: Formative assessment and the regulation of learning. Proceedings of the twentieth biennial conference of the Australian Association of Mathematics Teachers, Sydney. http://www.ncca.ie/uploadedfiles/primary/wiliam.pdf (accessed November 2015).

Wiliam, D. (2014, April). Formative assessment and contingency in the regulation of learning processes. Paper presented in a Symposium entitled Toward a Theory of Classroom Assessment as the Regulation of Learning at the annual meeting of the

American Educational Research Association, Philadelphia, PA, April 2014. http://www.dylanwiliam.org/Dylan_Wiliams_website/Papers_files/Formative\%20assessment\%20and\%20contingency\% 20in\%20the\%20regulation\%20of\%20learning\%20processes\%20(AERA\%202014).docx (accessed October 2015).

Willis, J. (2007). Assessment for learning - why the theory needs the practice. International Journal of Pedagogies \& Learning, $3(2), 52-59$.

Wright, A. (2001). The ABCs of assessment. The Science Teacher, 68(7), 60-64. 


\section{Appendix A}

\section{Teacher's Interview schedule (sample)}

o Do you communicate the learning objectives with students before you teach a topic? Or at any

point during the teaching of the topic?

o How does your assessment relate to the learning objectives?

o Do you explain to students your criteria for learning and what outcomes are expected?

o Do you ever allow peer-marking?

o Do you provide opportunities for students to re-work exam answers in class or otherwise?

o What is the effect of the final exam on your teaching? On your students?

o Do you use questions in your teaching/what types?

o What opportunities do you provide for students to participate in the learning process (e.g., by helping each other)?

o $\quad$ Do you provide tools for students to judge the quality of their work themselves?

o Were there any elements of self-assessment/peer learning groups that you particularly liked?

o How did you use the feedback you obtained from your students?

o Did you try the "comments-only"/delayed grades/no grades approach? How did that go with

the students?

o Can you identify any drawbacks in the use of assessment for learning (formative assessment) strategies?

o Would you continue to use assessment for learning strategies in your classrooms?

o Would you encourage other teachers to use these method in their classrooms? 


\section{Appendix B}

\section{Self-Assessment Feedback Sheet}

Name:

Date: Topic:

A. Consider today's (or this week's) biology lesson, and answer the following questions:

1. How well did the lesson(s) go for you? Successful _ Not successful

2. Did you understand why you were doing today's (this week's) topic? Yes No

3. How easy was the work done in today's (this week's) class?

Very easy easy fair difficult very difficult

4. How much thinking did you do in today's (this week's) class?

A lot A little Very little None

5. What was the best thing about today's (this week's) class?

6. What was the worst thing about today's (this week's) class?

7. What other comment would you state about today's (this week's) class?

8. How many of your stated learning goals did you achieve this week?

B. Consider the assignment you are handing in and answer the following questions:

1. What do you honestly consider will be a fair score/grade for the work you are handing in?

2. What do you think was the best thing you did in this assignment?

3. What did you find to be the hardest part of this assignment?

4. If you had to do this assignment again from scratch, what would you do differently? 